\title{
Influence of social connectedness, communication and monitoring on adolescent sexual activity in Ghana
}

\author{
Akwasi Kumi-Kyereme ${ }^{1}$, Kofi Awusabo-Asare ${ }^{1}$, Ann Biddlecom ${ }^{2}$, and Augustine Tanle ${ }^{1}$ \\ ${ }^{1}$ Department of Geography and Tourism, University of Cape Coast, Cape Coast, Ghana \\ 2 The Guttmacher Institute, New York, New York, United States
}

\begin{abstract}
This paper examines connectedness to, communication with and monitoring of unmarried adolescents in Ghana by parents, other adults, friends and key social institutions and the roles these groups play with respect to adolescent sexual activity. The paper draws on 2004 nationallyrepresentative survey data and qualitative evidence from focus group discussions and in-depth interviews with adolescents in 2003. Adolescents show high levels of connectedness to family, adults, friends, school and religious groups. High levels of adult monitoring are also observed, but communication with family about sex-related matters was not as high as with non-family members. The qualitative data highlight gender differences in communication. Multivariate analysis of survey data shows a strong negative relationship between parental monitoring and recent sexual activity for males and females, and limited effects of communication. Creating a supportive environment and showing interest in the welfare of adolescents appear to promote positive sexual and reproductive health outcomes.
\end{abstract}

\section{Keywords}

Adolescents; Ghana; connectedness; communication; monitoring; reproductive health

\section{Introduction}

\begin{abstract}
Worldwide, the high proportion of young people in the population, concern for the need for investing in the future of countries through its young people, and the challenges that the young generation face have led to increasing interest in their welfare. In reviewing the situation of young people and development, the UNFPA has observed that investing in young people will even facilitate the achievement of the Millennium Development Goals. ${ }^{1}$ For some countries in sub-Saharan Africa, the high levels of HIV infection and the continuing early and high fertility among young people provide additional impetus for investing in young people.

The home, as the initial focal point for investing in young people, is one of the many layers of environments for socialization. Providing avenues for child/parent (child/other adult) connectedness, communication, and monitoring, the home is expected to serve as a stabilizing factor in the lives of young people. Other adults in the immediate environ, relationships and agents such as peers, community members, schools and religious establishments as well as the broad socio-political system constitute the other layers
\end{abstract}

\footnotetext{
${ }^{1}$ In the context of Ghana, household is used in place of family in the original model.

${ }^{1}$ This is a special home for children under 18 years of age who have committed offences.
} 
involved in the transmission and acquisition of knowledge and experiences, networking and support systems for young people on a wide range of issues including sexual and reproductive health.2-5 Encouraging positive child/parent (child/other adult) connectedness, communication and monitoring is based on the assumption that such relationships between parents and children can lead to positive attitudes to life and lower levels of risk-taking behavior, especially in sexual and reproductive health. $6^{-} 8$

This study examines aspects of child/parent (child/other adult) connectedness, communication and monitoring among male and female adolescents (ages 12-19 years) in Ghana, using the bio-ecological framework as the model for analysis. It deals with the roles of parents, other household members, friends, schools and religious institutions in the lives of adolescents with respect to sexual behavior. The paper is based on a nationallyrepresentative survey conducted in 2004 among 12-19 year olds and qualitative evidence from focus group discussions (with 14-19 year olds) and in-depth interviews (with 12-19 year olds) in 2003 and 2004, respectively.

\section{Conceptual Framework}

The bio-ecological systems framework, originally developed by Bronfenbrenner ${ }^{2}$, defines a complex web of environments that influence the development of a child (Figure 1). The first, the microsystem, involves the child and the range of immediate relationships and interactions around the child. This layer of immediate environment includes parents and other adults in the household, neighborhood, school and friends. The next is the mesosystem of inter-relationships which deals with relationships between contexts in the microsystem (e.g., how families link to schools). The exosystem, the larger social system, defines the community-based systems and activities, some of which are tangentially related to the child such as the place of work of parents. ${ }^{9}$ The final environment, the macrosystem, comprises the cultural values, customs, laws, and the political system within which parents and children live. The nature of these environmental contexts of relationships (microsystem family, friends, peers, school), community (exosystem) and the society (macrosystem) define the range of possible influences on a person.

The microsystem of the home provides the layer that is closest to the child and, therefore, has a profound influence on the child. The rest of the environments, including the wider social system (exosystem), are expected to complement the primary role of parents and other adult members within the system. For instance, the school system and religious affiliation are expected to provide part of the knowledge and moral education of the child. ${ }^{9}$ Although expected to be complementary, some of the messages could be contradictory as well as compete with the general interest of the community. For instance, while the mass media provides an avenue for learning, some of the images could be challenging to parents and teachers. One of the roles of parents and other adults, therefore, will be to provide an environment which will counteract some of the possible negative images through levels of connectedness, communication and monitoring.

Connectedness describes the nature of relationships that provides the individual with support, security and direction. It also creates an environment within which one grows up and derives support and inspiration. One would expect that the more connected adolescents are to other adults, friends and key social institutions (such as religious organizations and social groups), the lower their likelihood of engaging in sexual risk-taking behavior. One measure commonly used to reflect connectedness between adolescents and family is simply whether a child lives with the mother, father or parent-figure in the same household. Studies of the relationship between parental coresidence and sexual activity generally show a negative relationship (coresidence is associated with a lower likelihood of being sexuallyexperienced). One survey-based study in a slum in Nairobi, Kenya, found that when the 
father lived in the household, his never-married 12-19 year old daughters were less likely to have ever had sex, to have had an unwanted pregnancy or to have been recently sexuallyactive than when neither parent or only the mother lived in the household. ${ }^{10}$ Therefore, it is expected that high levels of connectedness will be associated with positive sexual reproductive health outcomes among young people.

Communication includes the interactions and discussions that parents, other adults and peers have with young people on issues that are of interest or pertinent to one or both parties involved, as well as the content, nature and timing of the action. The expectation is that positive communication between young people and parents, other adults and peers will lead to positive behavioral outcomes, including those on sexual and reproductive health. A number of studies in Ghana and other sub-Saharan African countries have shown that parent-child communication about sex-related matters is relatively uncommon, and is fraught with discomfort, especially communication with fathers. ${ }^{1-13}$ Evidence from Ghana on the relationship between family communication about sex and the sexual behavior of adolescents is decidedly weak. One study of 1998 nationally-representative survey data from Ghana of 12-24 year olds found that communication with family members about avoiding sex was negatively associated with ever having had sex for unmarried males but had no effect for unmarried females. ${ }^{14}$ Communication with family members about contraceptive methods was positively associated with ever having had sex for both unmarried females and males, a finding which runs counter to the expectation that more open communication makes for lower levels of sexual behavior; this begs the question of which came first, having sex or talking about contraceptives. There were no associations between family communication about sex or contraceptives with number of lifetime partners or having multiple, recent sex partners and no consistent effects of family communication on condom use at first or last sex among unmarried females and males. ${ }^{14} \mathrm{~A}$ small scale study of adult and peer educator contacts with adolescents found no significant association between communication with adults or peers and practicing abstinence. ${ }^{15}$

Monitoring of young persons involves parents and other adults knowing where their children/wards are at any point in time, what they do with their free time or who they spend time with when they are not at home, in school or any organized activity. ${ }^{6}$ While in some societies monitoring is done solely by parents, in others it involves a wide range of adults and significant persons. The latter aspect underlies the oft-quoted statement that 'it takes a village to bring up a child.' Part of the essence of monitoring is to ensure that children or wards avoid risky environments and behaviors. It is expected that high levels of parental or guardian monitoring will lead to less adolescent sexual risk-taking behavior. Also, given the gender relations in Ghana including aspects such as virginity before marriage for females but not for males, it is expected that monitoring will be higher for females than males.

Connectedness, communication and monitoring occur as part of the social contexts in which young people live and together they are expected to promote good behavior as well as lead to attitudinal and behavioral change. Studies that test the relationship of both adult communication and monitoring with adolescent sexual behavior in Ghana or other subSaharan African countries are virtually non-existent. Other research, much of it focused on adolescents in low income communities in the United States, shows mixed evidence for the effect of communication on adolescent sexual or contraceptive behavior; yet there is strong evidence that parental monitoring — such as knowing where one's children are at night or knowing who children's friends are-is negatively associated with adolescent risk behaviors (such as premarital sexual intercourse or substance use). ${ }^{6 ;} 16^{-18}$

The contribution of this study is that it shows the degree to which unmarried adolescents in Ghana are embedded in various social contexts (via connectedness, communication and 
monitoring measures) and the associations these relationships have with adolescent sexual activity. Understanding the influence of the wider social context will help programmatic efforts in Ghana and other countries to appropriately involve adults, friends as well as social and faith-based institutions in improving HIV, STIs and pregnancy prevention among adolescents.

\section{Setting}

One out of every five Ghanaians is aged 10-19 years out of an estimated 18.9 million from the 2000 Census of Population and Housing. Household structure in Ghana is such that it consists of a range of related and non-related members, with children (37\%) and other relatives (22\%) accounting for $59 \%$ of household members. ${ }^{19}$ As observed by Nukunya, "(I)n many societies [in Ghana], even after marriage, the bride can remain with her parents until the first two or three children are born".4 (p.

Ghana is ethnically heterogeneous and includes the matrilineal Akan (49\%), and the patrilineal Ga-Dangme (8\%), Ewe (13\%), Mole-Dagbani (17\%) and other groups. Although ethnically heterogeneous, there seems to be a similar philosophy on the socialization of children. In all the groups, parents are expected to be responsible for the monitoring of their children, but the complex household structure is such that biological parents are not necessarily the ones responsible for communication and monitoring of children on a wide range of issues, including sexual and reproductive health. For example, Oppong ${ }^{20}$ has observed that among the Dagbon (sub-group of the Mole-Dagbani) parents are not considered to be the best people to bring up children, leading to a high level of fostering in this group. In general, though, parents and the other household members are involved in the monitoring of young people, especially females, in part because they are expected to ensure chastity before marriage. Girls who became pregnant before rites of passage were ostracized as this cast a slur not only on the image of the girl but also the corporate clan. Among all the ethnic groups, community leaders constitute a second tier of members, after parents and other household members, for monitoring the behavior of young people. As custodians of tradition, traditional leaders were responsible for initiation ceremonies. A third tier was play/ age mates, who often compensated for inadequate parent-child contact.23

All three of these tiers of communication and monitoring are undergoing changes due to the influences of education, urbanization and migration.24 Young people growing up are influenced by the traditional structures, issues of the modern state such as the laws, regulations and the socio-political system and the wider dimensions of globalization. With the technological revolution, Ghanaian youth are using mobile phones, internet and the other latest developments as other young people the world over. ${ }^{24}$ Despite these broad changes taking place, parents and other adults may not yet be eclipsed in terms of influencing adolescent sexual and reproductive health. It is the nature of this role (via connectedness, communication and monitoring) and the potentially competing influences of friends, religious and other social groups on adolescent sexual activity that this study explores.

\section{Data and methods}

Data are from three sources: Focus group discussions (FGDs) with 14-19 year olds, in-depth interviews with 12-19 year olds, and a nationally-representative survey of 12-19 year olds. In 2003, 16 focus group discussions were conducted among in-school and out-of-school male and female adolescents from both urban and rural areas. Discussions were conducted with homogenous groups of adolescents, segregated by sex, urban/rural residence, and school status (in or out-of-school). Overall, each FGD had between 8 and 12 participants 
and discussions lasted an average of 2-21/2 hours. The discussions were tape-recorded, transcribed and translated from local languages into English.

In 2003, 102 in-depth interviews (IDIs) were also conducted among 12-19 year old males and females. The IDIs were designed to have an equal number of urban and rural residents, males and females, in-school and out-of school individuals. Among the respondents were 18 adolescents identified as being in especially vulnerable circumstances: These were street children, boys in a borstal institution, refugees and girls who have run away from home, some of whom were pregnant, and were in shelters and/or on the street. An in-depth interview methodology was used to explore why some young people are at possible risk of HIV, other STIs or unwanted pregnancy while others are not in ways that are not likely to be captured in structured survey interviews.

The IDIs and FGDs were conducted in three regions of the country - the Greater Accra, Ashanti and Northern Regions. The Greater Accra Region, where the national capital is located, is ethnically heterogeneous. Although the region is ethnically a Ga area, the group accounted for $30 \%$ of the region's population while the Akan constituted $40 \%$. The second region, Ashanti, is a predominantly Akan area and they accounted for $52 \%$ of the population in the region. The capital of the Ashanti Region, Kumasi, is the second largest city in the country and is centrally located and a nodal point for all north-south traffic in the country. The third region, Northern, is one of the least urbanized (27\%) compared to the national average of $44 \%$, and one of the least developed. Ethnically, it is dominated by the MoleDagbani (52\%). ${ }^{19}$ In 1999 nearly $70 \%$ of the population in the Northern Region was classified as poor while the proportion for the Greater Accra Region was 5\% and 28\% in the Ashanti Region.25

The third source of data is a nationally-representative, household-based survey of 12-19 year olds in early 2004. Interviews lasted about 45 minutes and the survey sample consisted of 4,430 adolescents - 2,201 females and 2,229 males. The survey questionnaires were translated (and back-translated) into major local languages and pre-tested. Informed consent was obtained for all adolescents and consent was also obtained from parents or guardians for unmarried adolescents aged $12-17$ years.

Measures for connectedness of adolescents include co-residence with parents or parentfigures, the number and sex of close friends, current school attendance, frequency of participation (if at all) in religious services and membership in any social group or club. For adolescents who either did not know where their biological parents were living or whose parents had died, questions were asked about whether there was someone such as a motherfigure (or father-figure) to them and whether they lived with them. The co residence measure thus refers to biological parents and parent-figures.

The communication measures are a set based on an open-ended question in the survey on the types of people who talked to the adolescent about sex-related matters. The phrase "sexrelated matters" was purposefully kept vague because prior questions had been about specific areas of reproductive health, and there was need for an additional measure about general issues of an intimate nature. That question was preceded by a statement that the questions were going to be about people who may have talked to the respondent about personal things.

Information about monitoring was from three questions about how much adolescents thought their parents or guardians knew about 1) where the respondent goes out at night, 2) what the respondent does with free time and 3) who the respondent's friends are. An index of parental monitoring was constructed by summing responses to these three questions. One point was assigned for parents "do not know", two points for "sometimes know" and three 
points for parents "always know." The range was from 3 to 9 points and the mean was from 7.3 among older males (age 15-19) to 8.1 among younger females (age 12-14). Three variables were constructed based on the distribution of parental monitoring: low (3-5 points), medium (6-8 points) and high ( 9 points).

The dependent variable of interest in this analysis is whether an adolescent had sexual intercourse in the 12 months prior to the interview. Other control variables included in the models of sexual activity are age, rural-urban residence and the household wealth quintile. Household wealth quintiles were constructed using the protocol from the Demographic and Health Surveys. ${ }^{26}$

The survey sample is restricted to unmarried adolescents aged 12-19 years because married adolescents ( $4 \%$ of females and less than $1 \%$ of males) are assumed to be already sexuallyactive. Getting pregnant is also normative within marriage while married adolescents are more likely to be influenced by a spouse rather than parents or other guardians. Frequency distributions and logistic regression models were used to examine the associations of connectedness, monitoring and communication with current adolescent sexual activity (i.e., whether they have had sexual intercourse in the 12 months prior to the survey).

\section{Results Connectedness}

Table 1 shows the levels of connectedness between adolescents and parents, close friends, schools, religious organizations and social groups. Among unmarried $12-19$ year olds, $42 \%$ of females and $45 \%$ of males lived with both parents (or parent-figures), $22-24 \%$ with the mother alone, and $24-30 \%$ without any biological parents or parent-figures. Few live with fathers alone.

Another level of interaction is with friends. From Table 1, adolescents tend to have a large network of friends (about 3-4 close friends of the same sex on average and 1-2 close friends of the opposite sex), and males tend to report a larger number of close friends on average than females. Mixed-sex friendships are common for males of all ages and increase for both females and males as they get older. Less than $5 \%$ of adolescents indicated that they did not have any close friends at all (data not shown).

School attendance is another avenue for interaction, friendship and connectedness with nonhousehold members. In situations where children are in boarding school, the school takes on an additional function of socialization and bonding among members. About nine in 10 of 12-14 year olds are currently attending school, with small differences between the sexes at this stage. The proportion in school at 15-19 years drops to $63 \%$ for females and $68 \%$ for males. Formal education, especially beyond the basic level, serves as a proxy for a variety of things that could postpone sexual activity — high expectations for the future and time occupied by other school-related activities.

Religion is a critical social institution for adolescents. Among all adolescents in the 2004 survey, more than nine in 10 said they had a religious affiliation and among those who did, $84 \%$ or more said religion was very important to them. ${ }^{27}$ With this as background, Table 1 shows that among unmarried adolescents, $91 \%$ of females and $85 \%$ of males reported attending religious services once a week or more often. Membership in a social group or club is much less common: $32 \%$ of females and $21 \%$ of males said they belonged to a social group. Of those who belonged to a social group, religion-based clubs dominated (such as church choir), ${ }^{28}$ suggesting a widespread role that religion plays in the lives of young people. 


\section{Communication}

In the context of this paper, communication on sexual behavior is defined as the persons who have talked about sex-related matters with the adolescent. Table 2 shows distributions from the survey data of different types of people who have talked with unmarried adolescents about these topics. Female adolescents (46\%) are more often talked to about sexual matters by family members than are males (28\%), and family involvement is more common among older than younger adolescents. The most common household member involved is the mother (33\% of females and $16 \%$ of males) and then the father (13\% and $12 \%$ of females and males, respectively). Aunts, uncles, grandmothers or grandfathers were mentioned by less than $10 \%$ of unmarried adolescents as source of information on sexual and reproductive health.

Relatively more adolescents mentioned people outside of household - in particular, teachers and friends - than related members as those who talked to them about sex-related matters. About one in four females and males had friends, usually of the same sex, who talked to them about sex-related matters, and this was much more common for older than younger adolescents. Teachers, another important "non-family" source, were mentioned by $26 \%$ of females and $20 \%$ of males, which taken together with friends means that more nonhousehold members talk to adolescents about sex-related matters than people within the household.

Evidence from the focus group discussions shows some of the challenges of intergenerational communication about sex-related matters. From the discussions it became evident that young people were prepared to discuss or seek advice on sexual and reproductive health issues from peers because peers were seen to be sympathetic and ready to listen. As pointed out in one female focus group discussion:

P1: In some homes it is a taboo to mention anything connected with sex. In such homes young people do not talk about their problems. They keep quiet at home and then talk to friends instead.

P2: We like our friends because we feel shy talking to our parents.

P1: My mother will beat me if I bring up any topic about sex for discussion.

-Females, 14-16 years old, urban, in school

Responses from the IDIs reinforce those from the survey and indicate that both mothers and fathers were more likely to talk to their daughters than their sons about avoiding early sex, especially within the context of formal education and pregnancy. Child/parent communication on sexual and reproductive health, when it occurred, was mostly in the form of instructions and left little room for discussion. As one 13 year old girl indicated: "My father had told me to abstain from sex." Another 13 year old girl stated that: "Father keeps on saying that I should never have sex before marriage." The inadequate communication between parents and adolescents on sex-related matters is steeped in the attitudes of some parents towards issues associated with sexuality. Norms for adolescent sexual behavior indirectly approve of male sexual activity but not for females. While females are expected to be virgins at marriage, the same is not expected of males. ${ }^{21}$ Therefore, parents advise sons to be careful, but 'warn' daughters about sexual encounters with boys.

Although mothers were more likely to be consulted than fathers, the perception of mothers as people to discuss these kinds of issues with was not wholly positive. From the focus group discussions, mothers could be classified into four types: those who were approachable (and were in the minority), those who always passed the buck and indicated that the child should go and ask someone else such as the grandmother or the father, those who shouted 
the children down any time a discussion was brought up about sexual and reproductive health, and those mothers who were thought to have discussed their problems with others. Such mothers were referred to as 'gossipers'.

Some mothers have 'okro' mouth (they cannot keep (secrets) their mouths shut). If you tell them anything they will in turn inform your father and when that happens you are dead!

— Female aged 17 years

Fathers were described as tyrants who did not listen and also took action against their children's friends of the opposite sex, especially male friends who visited their daughters. As one of the young women stated:

You know, some parents are strict and therefore you cannot discuss some of these things with them. When I was in junior secondary school, a boy visited me in the house. My father came out and suspected that the boy was my boyfriend. My father knocked the boy down and when he got up he took off. At school the next day he told the other boys about his experience and advised the other boys not to visit me in the house. Such parents can embarrass you at times.

— Female aged 17 years

Due to the inadequate communication on sex-related matters between adolescents and adults, when some of the girls encounter unwanted sex they are unable to inform or discuss the experience with parents. Some girls may not even report non-consensual sex to parents because they (the children) fear of being punished or blamed for allowing that to happen to them. Thus, in one IDI, a 14 year old girl who was raped and became pregnant could not inform her parents because she had been warned about interacting with males.

Interviewer: After the sexual intercourse who did you report to?

Respondent: I did not tell anybody because my father had already warned me about them (Teachers in Training) and had told me not to fetch water for them again. So I was afraid to tell my parents.

Interviewer: Did he warn you not to tell anybody? Respondent: No, he did not. But I was afraid that if I told my parents my father will beat me.

The experience above illustrates aspects of communication gap between parents and children on sex-related matters even when they live in the same household. While some parents/adults are sources of information on sex-related matters, others have not created the necessary environment and relationship with their adolescent children for them to feel confident about discussing sexual and reproductive issues with them. Traditionally, child/ adult discussions on sex-related matters were not wholly with parents but other significant adults - aunts, grandparents and older members of the community - from the microsystem. When parents were not directly responsible for discussing sex-related matters with children, especially males with their daughters, it removed part of the embarrassment associated with discussing sexual issues with one's own children. But the role of this second tier of the traditional mode of communicating sexual and reproductive health matters to young people seems to be breaking down.

It appears that teachers and the school system are replacing the traditional household members as source of information on sex-related matters, and with over $90 \%$ of young adolescents in school and the introduction of population and family life education in the formal school system, this is not so surprising. This implies that the school system and teachers should be given the necessary support for them to become the second-tier of information after parents within the micro environment of the child. Being professionals, 
they are more likely to give credible information and advice than peers who may not have gone through any formal peer education program. Also by providing information through the school system, older siblings can be sources of information for their younger siblings.

\section{Monitoring}

An important role that parents and guardians play in shaping the sexual and reproductive health behavior of their children is simply being aware of what their children are doing and who their friends are. By being aware of the friends and movements of their children and wards, adults are able to influence their behavior. Table 2 shows the assessment of adolescents of the level of awareness of their parents or guardians about where they go at night, what they do with their free time and who their friends are. The results show clear age and sex differences in perceived levels of monitoring: more adolescent females than males of the same age report that their parents or guardians "always know" where they go at night, what they do with their free time and who their friends are. High parental monitoring (i.e., reports that parents "always know") decreases as adolescents grow older (comparing 12-14year-olds to 15-19-year-olds). Even among 15-19-year-old males, more than half say their parents or guardians always know where they are at night, who their friends are and how they spend their free time.

On the overall level of monitoring (last panel of Table 2) female adolescents are about one and half times more likely to be highly monitored than males, and the percentages being highly monitored are slightly higher among younger than older adolescents. Still in school and under the care of parents or other adults, more younger adolescents will understandably be highly monitored than older adolescents. Females are more likely to be monitored than males due to the attitudes towards female sexuality and expectations.

In spite of the level of monitoring, some adolescents may also try to conceal the identity of their friends from parents. For instance, a 19-year-old girl who was in a relationship had to make sure that her aunt, with whom she was staying, did not get to know about her boy friend:

Interviewer: Did anybody know about your relationship?

Respondent: "Hey do not go there" nobody in my house wants to know that you even have a guy (boy) friend. If you are a guy and you step in my house you will be in trouble, because the moment you get in and you are looking for me, my aunt will question you: 'Do you want to see her? For what?', and when you say she is a friend, what she will tell you is "can't you take a guy as your friend" My aunt is very strict. Even my friends of the same sex can't stay for long when they visit me. So if I want to see anybody I have to go to school first, because I can't have visitors at home.

—Female, 19 years old, urban, in school

What this implies is that when guardians do not create a supportive environment for their wards to discuss sex-related issues with them, including introduction of their friends of the opposite sex, monitoring is unable to achieve its intended objective. The narration also indicates active enforcement which could also be counterproductive if not done within an atmosphere of support.

Table 3 shows unmarried adolescents who had ever had sex and those who had sex in the last twelve months prior to the survey. Among the younger adolescents (12-14 year olds) only $2 \%$ reported that they have ever had sexual intercourse and among the older adolescents (15-19 year olds), $24 \%$ of females and $15 \%$ of males have ever had sex. Of those who ever had sex, $69 \%$ of females and $64 \%$ of males had sex in the 12 months prior to 
the survey. In the next section, multivariate analysis is used to relate levels of connectedness, communication and monitoring to adolescents who have had sex in the last 12 months, and given the age patterns in reports of recent sexual activity, the analytical sample is limited to unmarried adolescents who are 15-19 years old.

\section{Multivariate analysis}

The general view is that high levels of connectedness among adolescents through regular communication with positive reinforcement, a circle of supportive friends and adult monitoring of activities will be related to positive sexual and reproductive health outcomes. That is, all things being equal, one would expect that a girl with parents or guardians who are aware of who her friends are, where she goes at night and what she does with her free time will be less likely to be sexually active than a girl of a similar age whose parents or guardians are not very aware of her activities and friends. It is also expected that those who are connected to an adult figure and also talk to them about sex-related matters will be less likely to initiate sex; and these associations are expected to vary by sex of respondent. These issues are captured in the logistic regression models shown in Table 4.

Three logistic regression models are shown separately for females and males. The first model has the connectedness measures, the second model adds in the communications measures, and the third model adds in the monitoring measures. The dependent variable is whether an unmarried 15-19 year old had sexual intercourse in the last 12 months. Adjusted odds ratios are shown: odds ratios greater than one mean that the likelihood of the outcome increases with the value of the independent variable and, in the case of a categorical variable, relative to the reference category.

The results on connectedness indicate that for adolescent females, living with both parents/ parent-figures does matter with respect to sexual activity (i.e., sex in the last 12 months) in model 1 . That is, females living with both parents were less likely to be sexually-active. The effects, however, disappear once parental/guardian monitoring is added to the model (model 3 ). For males, living with mother/mother-figure only was negatively associated with being sexually-active compared to those living with no parents/parent-figures in model 3 . The plausible explanation of the negative relationship between sexual activity and males living with mother/mother-figure could be the support and close monitoring that such women may give to their sons. But this is an issue that needs further investigation. The variation by gender may be due to more complex household living arrangements than are currently captured by these measures of co-residence with parents and parent-figures.

Being in school was negatively associated with recent sexual activity, an observation which is consistent with the general dampening effect of formal education on sexual activity among adolescents. ${ }^{27}$ The negative effects of education on sexual activity in the last 12 months persist for both females and males even after communications and monitoring measures are added to the model. Frequency of religious attendance and belonging to a social group or club had no statistically significant association with recent sexual activity. Anecdotes of young people using religious and club meetings to meet friends exist, but this is yet to be fully explored and is beyond the scope of this paper.

In terms of connections to peers, two general patterns of significant relationships emerge. The first is a positive association between having close friends of the opposite sex and being sexually active, an association that exists for both males and females. This is perhaps to be expected as reporting close friends of the opposite sex may also broadly capture a social life that increases the opportunities for intimate relationships with the opposite sex. There is also a negative association for females between having same sex (female) close friends and being 
sexually-active. For males this is not significant. The results point to the interest among parents in Ghana in promoting same sex friendships especially for their daughters.

Adult communication with adolescents about sex-related matters is not associated with sexual activity, with the exception of female and male adolescents whose fathers or fatherfigures talked to them about sex-related matters. For males there is a negative association between father talking to them and sexual activity, but for females the relationship is positive. As with prior studies, it is difficult to disentangle the causal direction between communication and behavior. Fathers may talk to their children as they begin to show signs of maturity (perhaps explaining the negative association observed in the data for male adolescents). Fathers may also eventually get involved in talking to their children about sexrelated matters when the situation is "bad enough"- -such as when an unmarried daughter is discovered to be sexually-active/pregnant or a son had impregnated a girl. Given the relatively low levels of contact adolescent daughters appear to have with fathers on sexual and reproductive health issues, the latter explanation seems plausible for the positive association between father communication and sexual activity of their daughters. Talking with friends or teachers does not have any significant association with recent sexual activity.

Monitoring, conceptualized as how well parents or guardians know the friends and movements of their adolescent children, has a statistically significant, negative association with the recent sexual activity of unmarried adolescents. The negative relationship between monitoring and recent sexual activity holds for both males and females and shows gradations in effect by level of monitoring for females but not for males. For both females and males high monitoring is negatively associated with being sexually-active.

The evidence suggests that what matters is that parents keep a close eye on their children (know where they go out at night, how they spend their free time and who their friends are). This association was found to be the case for males and females, confirming similar observations in the United States. ${ }^{6}$ Knowing who one's child or ward goes out/moves with indicates interest in the adolescent's well-being and can provide a psychological support for the young person. Secondly, for females, associating with other females has a protective effect; and finally formal education is important in dampening the effect of sexual activity for both males and females.

The effects of the control variables were for the most part in expected directions. The association between age and the likelihood of recent sexual activity was positive for both females and males. Urban residence was not associated in a statistically significant way with sexual activity. Agyei et al. observed higher levels of sexual activity among females in urban than rural areas, but other studies have observed early sexual activity among females in rural than urban areas.27;29 There was a significant negative association for females between sexual activity and high socioeconomic status (as proxied by where an adolescent's household fell in the distribution of household wealth), but not the same for males.

\section{Conclusion}

Meeting the reproductive health needs of adolescents is one of the major challenges facing countries in sub-Saharan Africa since the quality of the population for investment and future development will depend upon the health of the younger generation. This challenge is directly captured in three of the Millennium Development Goals (MDGs), namely, promoting gender equality and empowering women, improving maternal health and combating HIV/AIDS. Meeting the challenges needs new insights into the behavior of adolescents and the support they receive or available to them. 
The analyses presented in this paper provide some new insights into the social environments and people that influence the sexual behavior of adolescents. While parents and other adults have traditionally played important roles in meeting the sexual and reproductive health needs of adolescents, their domain as the first environment for information on sexual and reproductive health matters appears to be eroding. Grandparents are no longer one of the major sources of communication about sex-related matters for adolescents. Rather, peers and the school system have become important sources: the school due to the growing importance of formal education and peers as people of immediate contact. The strong negative association observed between formal education and being sexually-active reinforces the emphasis that has been given to formal education, especially for girls, as one of the strategies for achieving positive sexual and reproductive health outcomes.

Clear gender differences emerge in terms of the strategies that parents/guardians adopt towards adolescents and the approaches fathers and mothers pursue to address sexual and reproductive health matters. Due to the gender-based perception of female and male sexuality, daughters tended to be monitored more than sons and the approach was to caution daughters to avoid pregnancy while sons were admonished to be careful. Based on the evidence from the qualitative data, it appeared that the approach of parents and other adults was more of talking to their children/wards rather than creating environments for dialogue and discussion, pointing to the traditional gap in communication in sexual and reproductive health between parents and children. The perception of some fathers as being autocratic appeared to create a barrier between them and their children/wards. Hence, some of the children could not discuss sexual and reproductive health matters even when they had problems. Secondly, it seemed fathers talked to their daughters after they have become sexually active or pregnant. Mothers, although generally considered to be sympathetic, were also not found to be wholly helpful with information about sexual issues in some cases. There is also little support for interventions that focus on increasing parent-child communication about sex as a way to delay the start of sexual activity, possibly due to the approach of preaching to them rather than creating conditions for discussion. Instead, the findings provide support for the important role that parents and other adults can play in the lives of their children/wards by being more involved in how the children spend their time and with whom they associate.

The findings have profound implications for programming for adolescent sexual and reproductive health. Creating a supportive environment and the perception of parents/ guardians being available and interested in their welfare will help promote connectedness, which may in turn lead to better communication and positive sexual and reproductive health outcomes for adolescents. One of the strategies is to target parents and other adults in community settings to enable them to develop their skills and attitudes and be able to assist in meeting the sexual and reproductive health needs of their children/wards. The home provides an important starting point in establishing connectedness, communication on a wide range of issues, including sexual and reproductive health and monitoring of activities. Beyond parents and significant adults, friends and social institutions such as the school system provide information on as well as influence the sexual and health needs of adolescents. Harnessing these potentials can contribute to achieving the purpose and spirit inherent in the three MDGs that directly relate to the health of adolescents, especially females.

\section{Acknowledgments}

We are grateful for contributions to the overall study from colleagues at the Guttmacher Institute (United States), University of Cape Coast (Ghana), Institut Supérieur des Sciences de la Population (Burkina Faso), African Population and Health Research Center (Kenya), Centre for Social Research (Malawi) and the Makerere Institute of 
Social Research (Uganda). This study was supported by The Bill \& Melinda Gates Foundation, The Rockefeller Foundation and the National Institute of Child Health and Human Development (Grant \# 5 R24 HD043610).

\section{References}

1. United Nations Population Fund. UNFPA state of world population 2004 - The Cairo Consensus at Ten: Population, Reproductive Health and the Global Effort to End Poverty. New York, NY: UNFPA; 2004.

2. Bronfenbrenner, U. The ecology of human development. Cambridge, MA: Harvard University Press; 1979.

3. Clark, G. Onions are my husband: Survival and accumulation by West African market women. Chicago: Chicago University Press; 1994.

4. Nukunya, GK. Tradition and change in Ghana: An introduction to sociology. 2. Accra, Ghana: Ghana Universities Press; 2004.

5. Olson, D.; DeFrain, J. Marriage and family: Diversity and strengths. Mountain View, CA: Mayfield Publishing Company; 2000.

6. DiClemente RJ, Wingood GM, Crosby R, Sionean C, Cobb BK, Harrington K, et al. Parental monitoring: Association with adolescents' risk behaviors. Pediatrics 2001;107(6):1363-1368. [PubMed: 11389258]

7. Beck KH, Shattuck T, Haynie D, Crump AD, Simons-Morton B. Associations between parent awareness, monitoring, enforcement and adolescent involvement with alcohol. Health Educ Res 1999;14(6):765-775. [PubMed: 10585384]

8. Sieverding JA, Adler N, Witt S, Ellen J. The influence of parental monitoring on adolescent sexual initiation. Arch Pediatr Adolesc Med 2005;159(8):724-729. [PubMed: 16061779]

9. Berk, LE. Child Development. 5. Boston, MA: Allyn and Bacon; 2000.

10. Ngom P, Magadi MA, Owuor T. Parental presence and adolescent reproductive health among the Nairobi urban poor. J Adolesc Health 2003;33(5):369-377. [PubMed: 14596958]

11. Ampofo AA. "When men speak women listen": gender socialization and young adolescents' attitudes to sexual and reproductive issues. Afr J Reprod Health 2001;5(3):196-212. [PubMed: 12471941]

12. Ghana Social Marketing Foundation (GSMF). Ghana youth reproductive health survey report. 2000. Planned Parenthood Association of Ghana, Population Communication Services JHU, USAID, Focus on Youth Project. JHU, CCP, PCS

13. Amuyunzu-Nyamongo, M.; Biddlecom, AE.; Ouedraogo, C.; Woog, V. Qualitative evidence on adolescents' views of sexual and reproductive health in sub Saharan Africa. New York: Alan Guttmacher Institute; 2005.

14. Karim AM, Magnani RJ, Morgan GT, Bond CC. Reproductive health risk and protective factors among unmarried youth in Ghana. Int Fam Plan Perspect 2003;29(1):14-24. [PubMed: 12709308]

15. Wolf RC, Pulerwitz J. The influence of peer versus adult communication on AIDS-protective behaviors among Ghanaian youth. J Health Commun 2003;8(5):463-474. [PubMed: 14530148]

16. Bettinger JA, Celentano DD, Currieri FC, Adler NE, Millstein SG, Ellen JM. Does parental involvement predict new sexually transmitted diseases in female adolescents? Arch Pediatr Adolesc Med 2004;158:666-670. [PubMed: 15237066]

17. Li X, Feigelman S, Stanton B. Perceived parental monitoring and health risk behavior among urban low-income African American children and adolescents. J Adolesc Health 2000;21:43-48. [PubMed: 10867351]

18. Roche KM, Mekos D, Alexander CS, Astone NM, Bandeen-Roche K, Ensminger ME. Parenting influences on early sex initiation among adolescents: how neighborhood matters. J Fam Issues 2005;26(1):32-54.

19. Ghana Statistical Service. 2000 Population and housing census: Summary report of final results. Accra, Ghana: Ghana Statistical Service; 2002.

20. Oppong, C. Growing up in Dagbon. Accra, Ghana: Ghana Publishing Corporation; 1973.

21. Nukunya, GK. Kinship and marriage among the Anlo-Ewe. New York: Athlene Press; 1969.

22. Sarpong, PK. Ashanti nubility rites. Tema, Ghana: Ghana Publishing Corporation; 1977. 
23. Mandela, N. Long walk to freedom. London: Abacus; 1994.

24. National Research Council and Institute of Medicine, Panel on Transitions to Adulthood in Developing Countries. Growing Up Global: The Changing Transitions to Adulthood in Developing Countries. Washington, DC: National Academies Press; 2005.

25. Ghana Statistical Service. Poverty trends in Ghana in the 1990s. Accra, Ghana: Ghana Statistical Service; 2000.

26. Rutstein, SO.; Johnson, K. DHS Comparative Reports. Calverton, MD: ORC Macro; 2004. DHS Comparative Reports 6: The DHS Wealth Index.

27. Awusabo-Asare, K.; Abane, AM.; Kumi-Kyereme, A. Occasional Report No. 13. New York: The Alan Guttmacher Institute; 2004. Adolescent Sexual and Reproductive Health in Ghana: A Synthesis of Research Evidence.

28. Awusabo-Asare, K.; Biddlecom, AE.; Kumi-Kyereme, A.; Patterson, K. Occasional Report No. 22. New York: Guttmacher Institute; 2006. Adolescent Sexual and Reproductive Health in Ghana: Results from the 2004 National Survey of Adolescents.

29. Agyei WKA, Biritwum RB, Ashitey AG, Hill RB. Sexual behavior and contraception among unmarried adolescents and young adults in greater Accra and eastern regions of Ghana. J Biosoc Sci 2000;32:495-512. [PubMed: 11075642] 


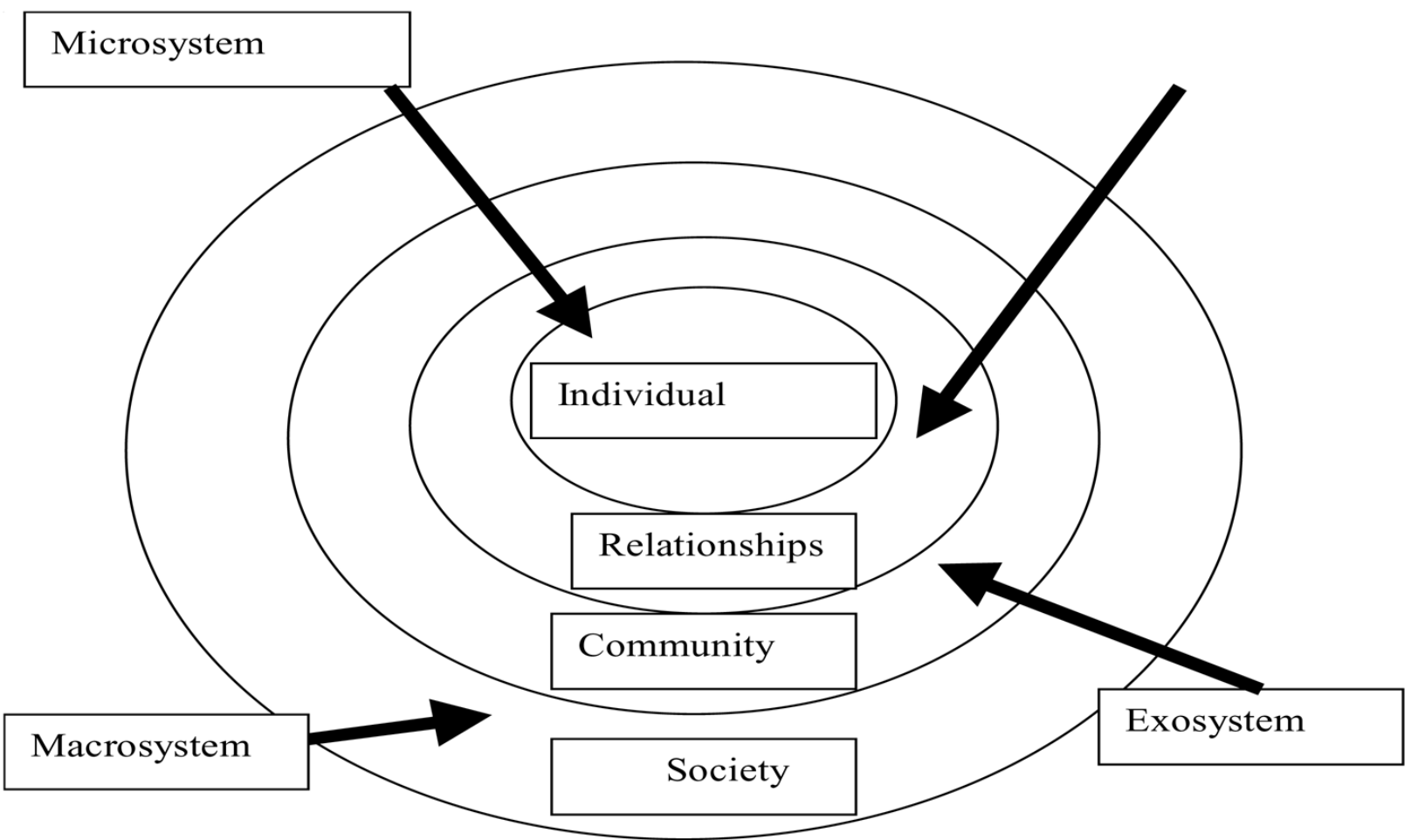

Figure 1.

Human Bio-Ecological Model 


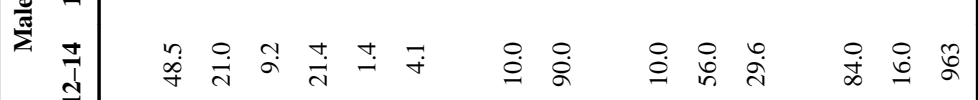




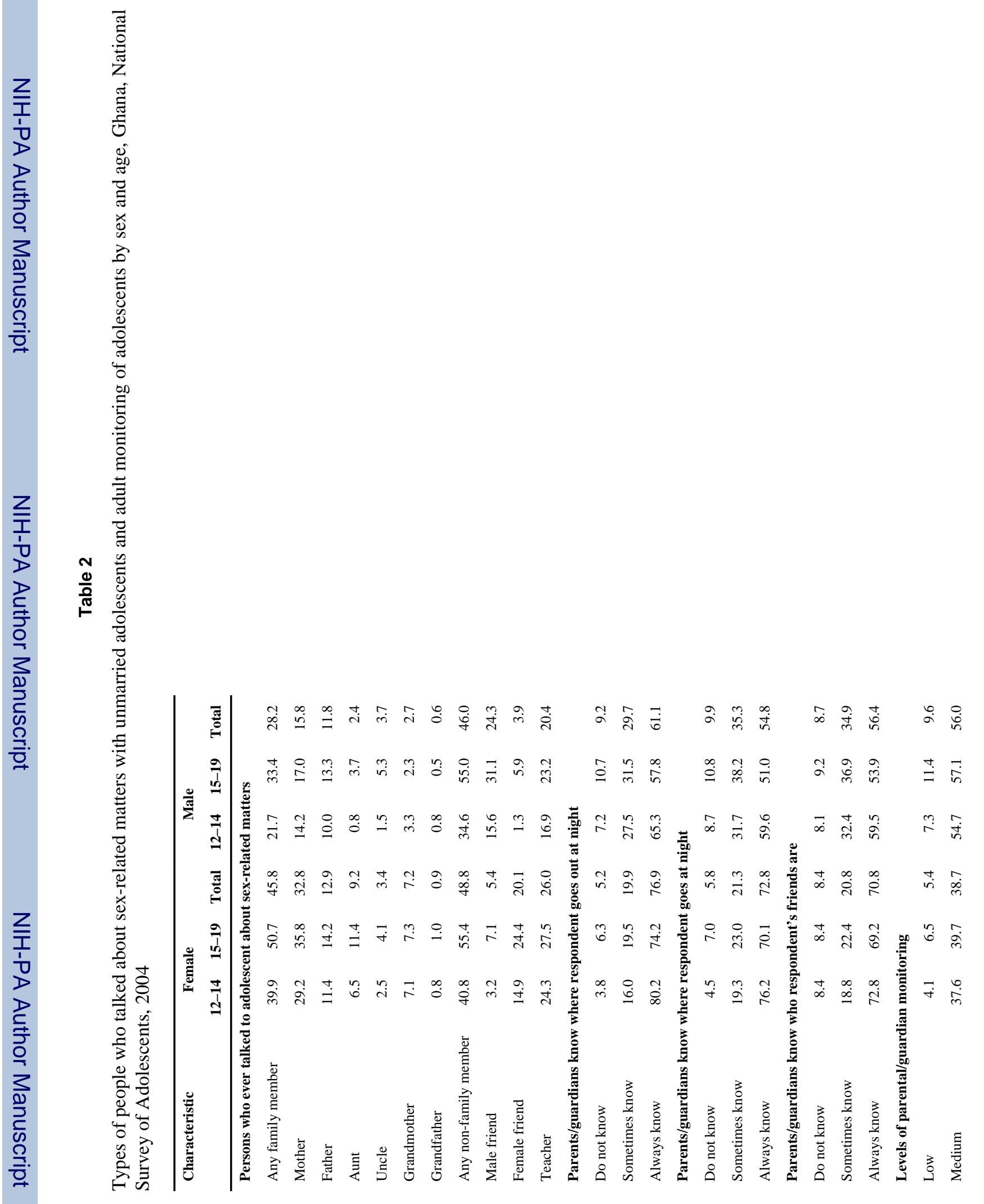




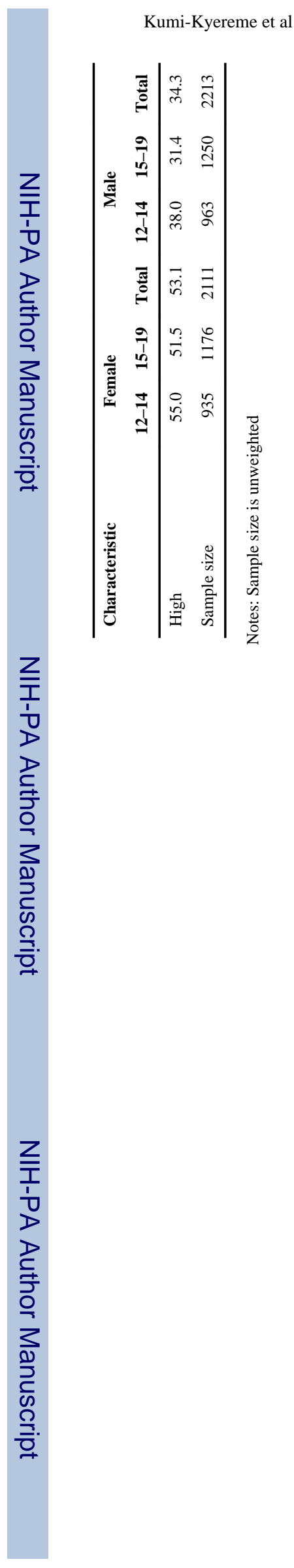

Page 18 


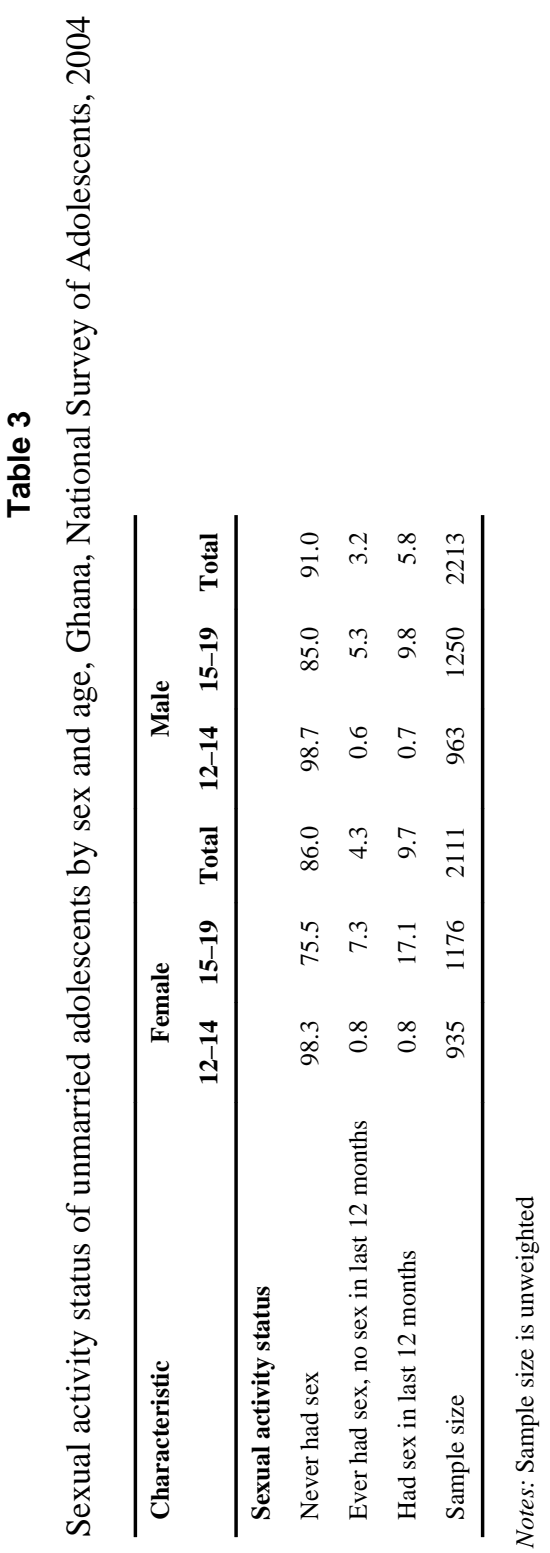

Afr J Reprod Health. Author manuscript; available in PMC 2008 May 5. 


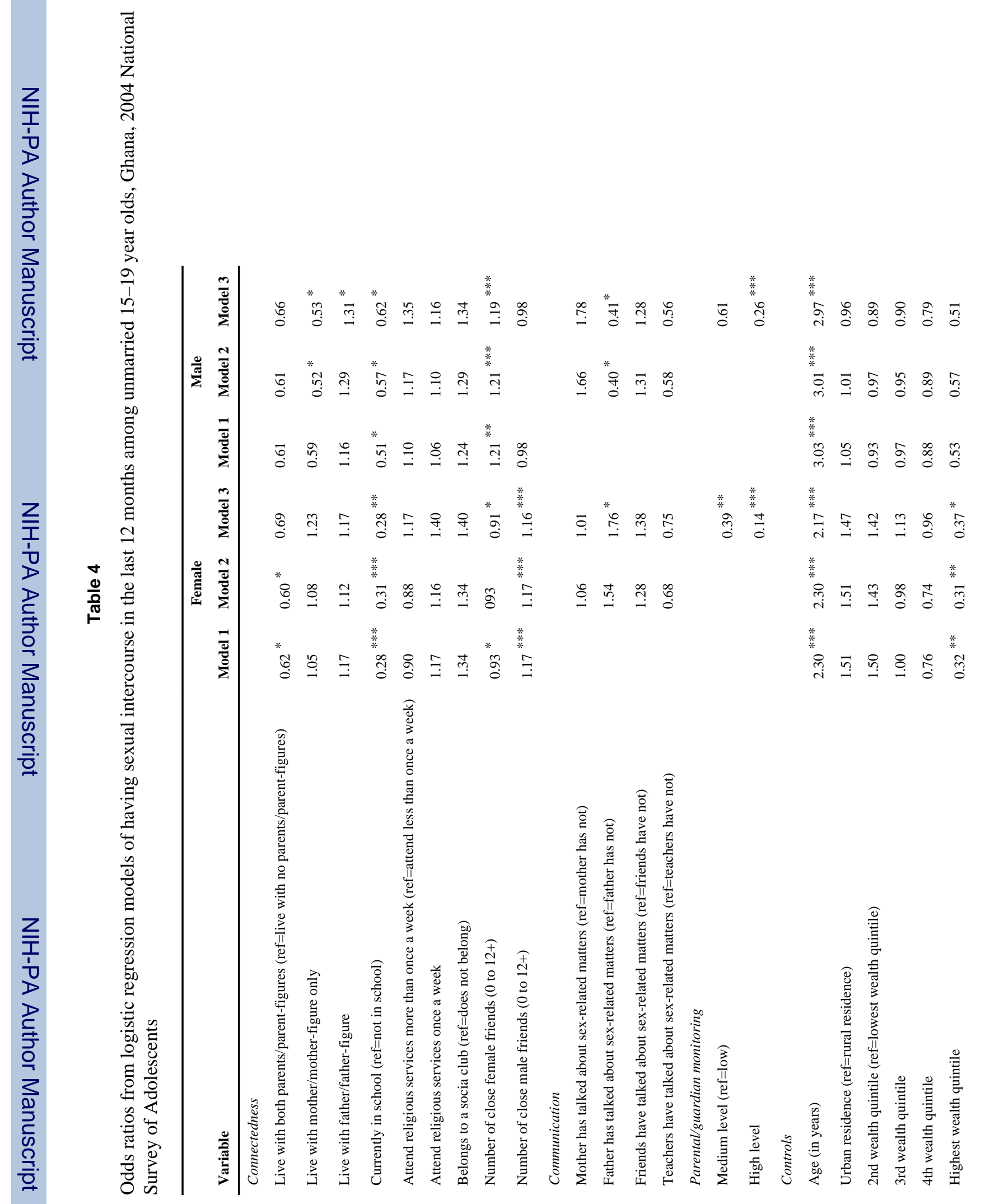




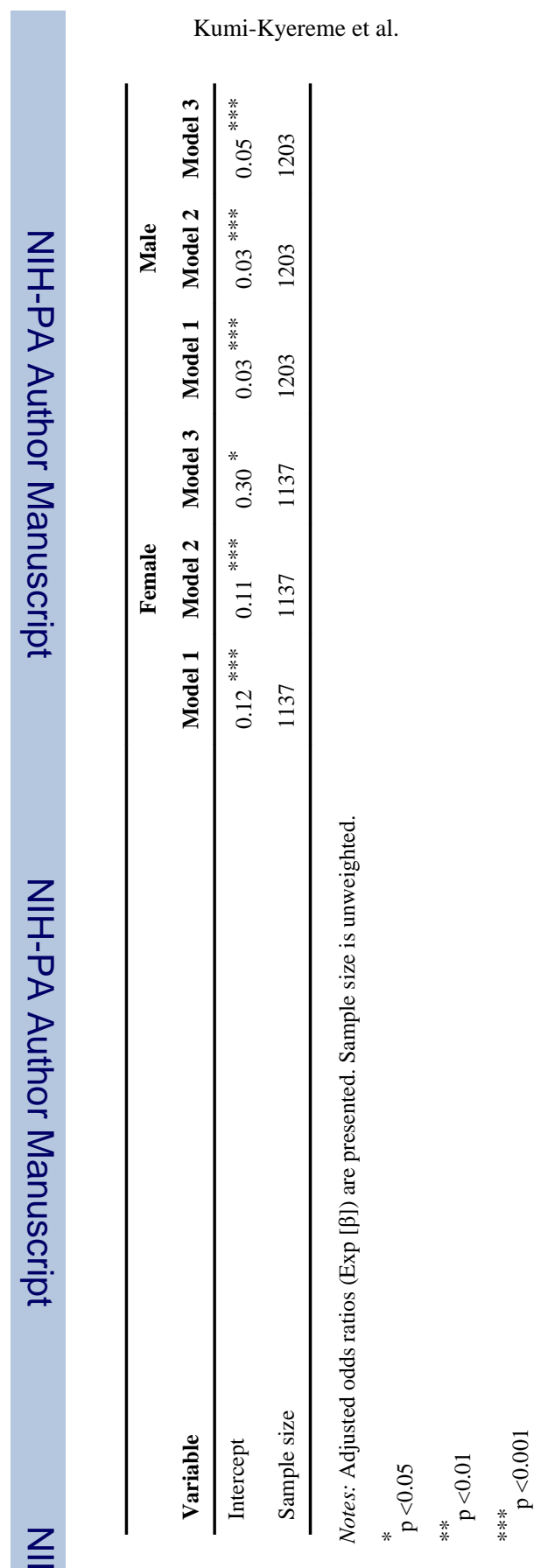

Afr J Reprod Health. Author manuscript; available in PMC 2008 May 5. 